\section{Microbial Production of Gold Nanoparticles}

\author{
Mariekie Gericke and Anthony Pinches \\ Biotechnology Division, Mintek, Private Bag X3015, \\ Randburg, 2125, South Africa \\ e-mail: mariekieg@mintek.co.za
}

\begin{abstract}
The development of techniques for the synthesis of nanoparticles of well-defined size, shape and composition is a challenge and an important area of research in nanotechnology. Many microorganisms have the ability to produce inorganic nanostructures and metal nanoparticles with properties similar to chemically-synthesised materials, while exercising control over the size, shape and composition of the particles. This alternative approach to chemical synthesis procedures uses microbial systems for the production of nanosized materials. Intracellular synthesis of gold nanoparticles, as well as extracellular formation of nanoparticles in the presence of fungal cell extract has been successfully demonstrated. The possibility to manipulate the size and shape of gold nanoparticles by altering key growth parameters was investigated and the results have provided some understanding as to which parameters may have an effect on the formation of gold nanoparticles.
\end{abstract}

\section{Introduction}

Metal nanoparticles exhibit unique electronic, magnetic, catalytic and optical properties that are different from those of bulk metals $(1,2)$. Gold nanoparticles, in particular, are of interest, mainly due to their stability under atmospheric conditions, resistance to oxidation and biocompatibility (3-6). These unique properties can potentially be exploited in a diverse range of industrial applications using their optical and electronic properties in optics, electronics, medical diagnostics and treatments, sensors and coatings $(3,4,7)$.

The development of techniques for the controlled synthesis of gold nanoparticles of well-defined size and shape is a big challenge and numerous chemical methods, aimed at controlling the physical properties of the particles, are reported in the literature (7-9). Most of these methods are still in the development stage and problems are often experienced with stability of the nanoparticle preparations, control of the crystal growth, and aggregation of the particles $(2,6,8,10)$.

The use of microbial cells for the synthesis of nanosized materials has recently emerged as a novel approach for the synthesis of metal nanoparticles. Although the efforts directed towards the biosynthesis of nanomaterials are recent, the interactions between micro-organisms and metals have been well documented (11-14) and the ability of micro-organisms to extract and/or accumulate metals is employed in commercial biotechnological processes such as bioleaching and bioremediation.

Many microbes are known to produce inorganic nanostructures and metallic nanoparticles with properties similar to chemically-synthesised materials, while exercising strict control over size, shape and composition of the particles. Examples include the formation of magnetic nanoparticles by magnetotactic bacteria (15), the production of silver nanoparticles by Pseudomonas stutzeri (16), synthesis of nano-scale, semi-conducting CdS crystals in the yeast Schizosaccharomyces pombe (17), and the formation of palladium nanoparticles using sulphate reducing bacteria in the presence of an exogenous electron donor (18). The ability of bacteria, fungi, actinomycetes (19), yeast (20), algae (21) and plants (22) to accumulate gold ions from solution has been reported and the synthesis of gold nanoparticles has been successfully demonstrated in a range of organisms including Bacillus sp. (23), fungal species such as Verticillium and Fusarium (24,25), actinomycete such as Rhodococcus (26) and Thermomonospora (27) and lactic acid bacteria (28).

The interest also extends to the synthesis of nanostructures such as nanowires and the assembly of nanoparticles using biological templates such as DNA, proteins, S-layers and viruses $(29,30)$.

The objective of this paper is to review the progress that has been made at Mintek on the biosynthesis of gold nanoparticles. A variety of microorganisms have been screened for their ability to accumulate and reduce gold ions 
to form nanoparticles. In addition, the possibility to manipulate the size and shape of gold nanoparticles by altering key growth parameters was investigated.

\section{Experimental methods}

\section{Selection and isolation of cultures}

Pseudomonas stutzeri NCIMB 13420, Bacillus subtilis DSM 10, Pseudomonas putida DSM 291, Schizosaccharomyces pombe DSM 2791, Schizosaccharomyces pombe DSM 70576, Pichia jadinii UOFS Y-0156, Pichia jadinii UOFS Y-0520, Verticillium dahliae DSM 63083, Verticillium luteoalbum DSM 63545 and Fusarium oxysporum DSM 2723 were obtained from The National Collections of Industrial and Marine Bacteria (NCIMB), German National Resource Centre for Biological Material (DSM) and the yeast culture collection of the University of the Free State, South Africa (UOFS). These cultures were selected based on their ability to produce metal nanoparticles $(16,17,24)$ and accumulate gold from solution $(13,19,32)$.

In addition, a variety of bacterial, fungal and yeast cultures, isolated from soil and metal-rich dump samples, were included in the screening programme. Enrichment was performed in shaker incubators at $28^{\circ} \mathrm{C}$ in Erlenmeyer flasks containing universal yeast medium (YM) $(0.3 \%$ yeast extract, $0.3 \%$ malt extract, $0.5 \%$ peptone, $1 \%$ glucose, $0.15 \%$ agar) or nutrient broth. After $48 \mathrm{~h}$ growth, the cell suspensions were plated on YM, nutrient agar and potato dextrose agar plates. Individual colonies were picked and further purified by sub-culturing on agar plates. A variety of bacterial, fungal and yeast cultures isolated were included in the screening programme, but it should be noted that no attempt was made to identify the individual cultures.

\section{Screening of cultures for gold accumulation and nanoparticle synthesis}

Cultures were grown up in test tubes containing $10 \mathrm{ml}$ nutrient medium in shaker incubators at $28^{\circ} \mathrm{C}$. After 24 to $48 \mathrm{~h}$ incubation the biomass was separated from the medium by centrifugation (7500 rpm, $10 \mathrm{~min}$ ) and washed three times in sterile distilled water to remove any nutrient media that might interact with the gold ions. The biomass was resuspended in $10 \mathrm{ml}$ distilled water and the $\mathrm{pH}$ adjusted to between 5 and 6 with $0.2 \mathrm{M} \mathrm{NaOH}$. $\mathrm{HAuCl}_{4}$ was added to give an overall Au-concentration of $250 \mathrm{mg} / \mathrm{l}$. The mixture was left for a further 24 to $72 \mathrm{~h}$ in a shaker incubator at $28^{\circ} \mathrm{C}$. The accumulation and reduction of gold were followed by visual observation of the biomass turning purple, an indication of the formation of gold nanoparticles (Experiment 1).

\section{Effect of growth parameters on nanoparticle production}

Cultures were grown for 24,48 or $72 \mathrm{~h}$ as described above. The biomass was separated from the medium by centrifugation (7500 rpm, $10 \mathrm{~min}$ ) and washed three times in sterile distilled water before exposure to $\mathrm{HAuCl}_{4}$ at a $\mathrm{pH}$ level of 5 (Experiment 2).

The effect of $\mathrm{pH}$ on nanoparticle formation was evaluated by exposing $100 \mathrm{mg}$ of washed biomass in $10 \mathrm{ml}$ distilled water to $\mathrm{HAuCl}_{4}$ at an overall Au concentration of $250 \mathrm{mg} / \mathrm{l}$. The $\mathrm{pH}$ levels were adjusted to 3, 5, 7 and 9 respectively, followed by incubation at $28^{\circ} \mathrm{C}$ (Experiment 3).

Gold-containing cell suspensions (100 mg wet mass/10 ml solution) were incubated in shaker incubators at $25^{\circ} \mathrm{C}, 35^{\circ} \mathrm{C}$ and $50^{\circ} \mathrm{C}$ to evaluate the effect of temperature on nanoparticle formation. In all tests, the accumulation and the reduction of gold were followed by visual observation of the biomass turning purple (Experiment 4).

\section{Synthesis of nanoparticles in the presence of cell- free extract}

Verticillium luteoalbum biomass (100 mg wet mass/10 ml solution) grown in nutrient medium as described above, was separated from the medium by centrifugation (7500 rpm, 10 $\mathrm{min})$, washed twice in distilled water and the biomass resuspended in $10 \mathrm{ml}$ distilled water. The washed cells were transferred to a test tube and an equal volume of glass beads added, before the suspension was agitated at maximum speed using a vortex mixer. The cell suspension was examined microscopically until most of the cells were broken. Broken cells and those remaining intact were removed by centrifugation at $10000 \mathrm{rpm}$ for $10 \mathrm{~min}$. $\mathrm{HAuCl}_{4}(250 \mathrm{mg} / \mathrm{l})$ was added to the cell-free extract and the $\mathrm{pH}$ adjusted to 5 by addition of $0.2 \mathrm{M} \mathrm{NaOH}$. The mixture was incubated at $35^{\circ} \mathrm{C}$ and the accumulation and reduction of the metals were followed by observation of the suspension changing colour (Experiment 5).

\section{Characterisation of the nanoparticles}

Samples were prepared for TEM analysis by separating the biomass from the liquor by centrifugation and washed twice in sterile distilled water. The samples were fixed for 1 hour in 2.5\% gluteraldehyde in $0.075 \mathrm{M}$ phosphate buffer ( $\mathrm{pH} 7.4$ ), followed by 3 washes in $0.075 \mathrm{M}$ phosphate buffer. After a second fixation step of $1 \mathrm{~h}$ in $1 \%$ osmium tetroxide, the cells were washed in distilled water. The cell pellet was subjected to dehydration with $30,50,70 \%$ ethanol, followed by three dehydration steps in $100 \%$ ethanol. Infiltration of the resin was carried out by placing the pellet in 30\% Quetol in ethanol for 1 hour, followed by 1 hour in 60\% Quetol. After centrifugation, the pellet was resuspended in 100\% Quetol for $4 \mathrm{~h}$ before polymerisation at $65^{\circ} \mathrm{C}$ for 24 hours. Ultrathin sections were not stained prior to analysis, due to possible interference of the stain with the gold particles. TEM analyses were done on a Philips 301 transmission electron microscope.

For TEM analysis of the cell-free extract, a drop of the sample was placed onto a carbon-coated copper grid. After about a minute, the extra solution was removed using blotting paper and the grid air-dried before analysis. 

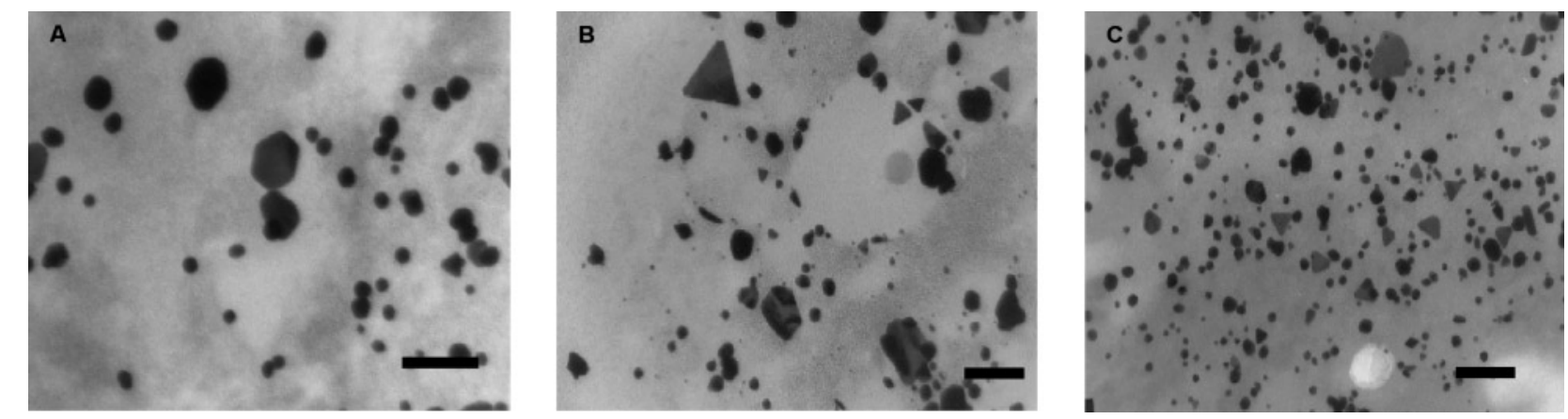

\section{Figure 1}

TEM images illustrating the formation of gold nanoparticles by (A) P. jadinii, (B) V. luteoalbum and (C) Isolate 6-3 after $24 \mathrm{~h}$ exposure to $\mathrm{HAuCl}_{4}$ (Scale bar $=100 \mathrm{~nm})$.

Elemental analysis on single particles was carried out on an air-dried, carbon coated sample using an energy dispersive spectroscopy (EDS) attachment on a Jeol 5800 LV scanning electron microscope using the following instrument conditions: accelerating voltage of $20 \mathrm{keV}$ and counting time of $100 \mathrm{~s}$.

\section{Results}

\section{Screening of microbes for their ability to produce gold nanoparticles}

The production of the nanoparticles after exposure of the cultures to gold was evaluated based on the size and shape of the particles, number of particles produced per cell and the occurrence of the particles in the cells as determined by transmission electron microscopy (TEM) - Experiment 1.

The most promising results were obtained with the yeast, P. jadinii (formerly Candida utilis) and the fungal cultures, Isolate 6-3 (isolated from a metal-rich dump) and $V$. luteoalbum (Figure 1). The biomass turned dark purple within a few hours after exposure to $\mathrm{HAuCl}_{4}$, while the solution remained colourless, an indication of intracellular nanoparticle synthesis.

In all three cases, the particles did not occur in preferential areas and were deposited throughout the cells. As in the case of previous results obtained with fungi $(24,25)$ various particle morphologies, which included spherical, triangular, hexagonal and other shapes were present in all three cultures (Figures 1 and 2). No clear relationship between the morphology of the nanoparticles and type of fungal biomass was observed. Large variations in particle size were observed and these varied from a few to approximately $100 \mathrm{~nm}$ in diameter. The images suggested that the spherical particles tended to be smaller than the hexagonal and triangular shaped particles.

\section{Control of the size and shape of intracellularly produced gold nanoparticles}

Although the initial screening results were promising and a variety of nanoparticles with interesting shapes were synthesised, it is realised that for most applications nanoparticles of well-defined size and shapes are required. In addition, for a biological process to successfully compete with chemical nanoparticle synthesis, very strict control over average particle size in a specific size range and uniform particle morphology is required. In an attempt to achieve better size and shape control, the effect of growth parameters such as growth stage of the cells, $\mathrm{pH}$ and temperature on the process was investigated using the two fungal cultures $V$. luteoalbum and Isolate 6-3.

Biomass grown for 24,48 and 72 h respectively was exposed to $\mathrm{HAuCl}_{4}$ for $24 \mathrm{~h}$ to evaluate the effect of the age of the culture on its ability to accumulate and reduce gold

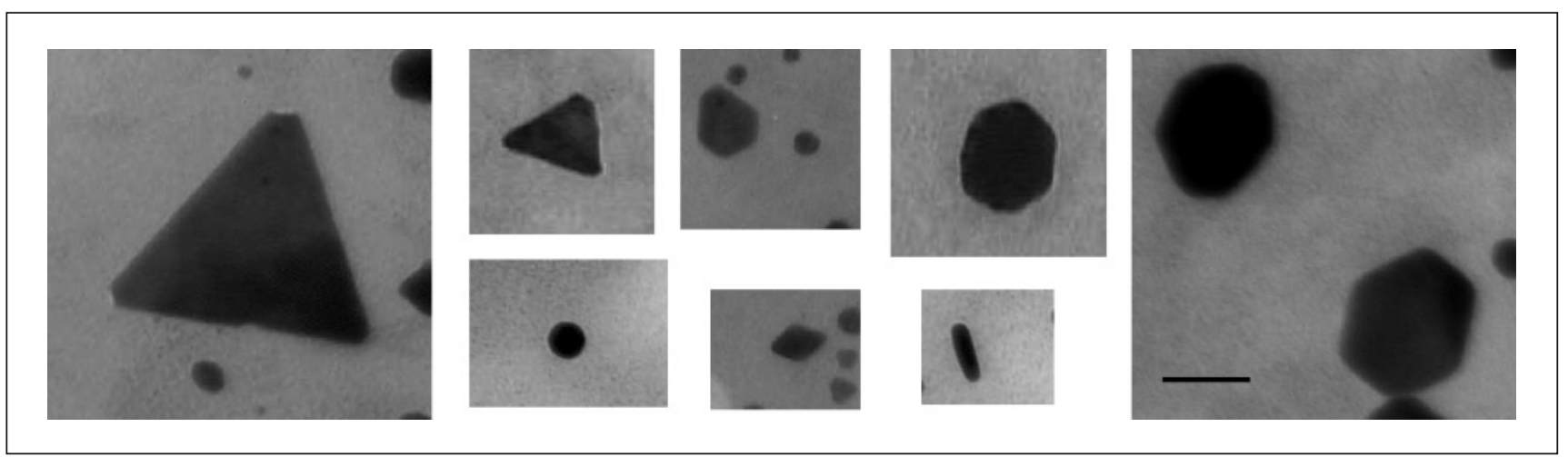

\section{Figure 2}

TEM images of a selection of different nanoparticles formed by reduction of $\mathrm{HAuCl}_{4}(\mathrm{Scale}$ bar $=50 \mathrm{~nm})$ 


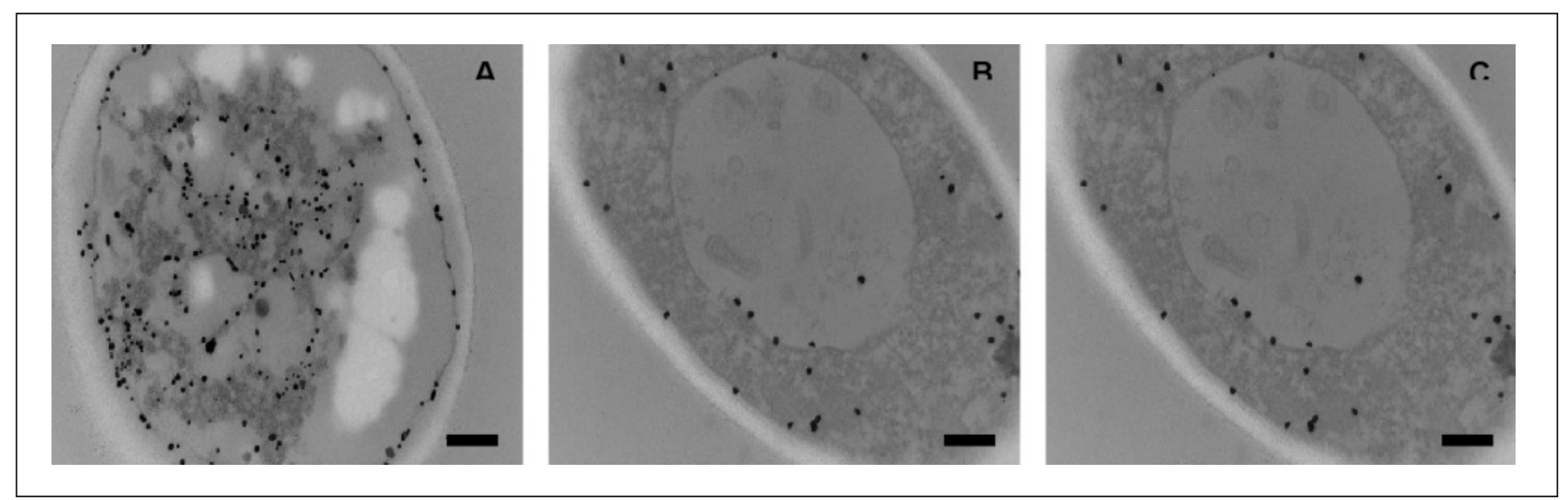

\section{Figure 3}

The effect of growth stage of the cells on the extent and appearance of nanoparticle formation in Isolate 6-3 at pH 5. (A) $24 \mathrm{~h}$ growth, (B) 48 h growth, (C) 72 h growth. (Scale bar $=200 \mathrm{~nm}$ )

ions (Experiment 2). It was shown that the age of the cells at the time of exposure to gold did not have an effect on the shape of the accumulated gold nanoparticles. However, with both $V$. luteoalbum and Isolate 6-3, a decrease in the number of particles per cell was observed when older cells, harvested later during the growth cycle were exposed to gold (Figure 3). A possible explanation might be that cells in early exponential phase of growth produce very high concentrations of enzymes and proteins that are actively involved in accumulation and reduction of the gold ions.

The $\mathrm{pH}$ was found to be an important parameter affecting gold nanoparticle synthesis in both cultures (Experiment 3). Variations in $\mathrm{pH}$ during exposure to Au-ions had an impact on the size, shape and number of particles produced per cell. Figure 4 shows representative TEM micrographs of nanoparticles produced in $V$. luteoalbum after 24 h exposure to $\mathrm{HAuCl}_{4}$ at $\mathrm{pH}$ levels of 3, 5, 7, and 9 respectively. Similar results were obtained with Isolate 6-3.

Particles formed at $\mathrm{pH} 3$ were predominantly spherical in shape, relatively uniform in size, with the majority of the particles having less than $10 \mathrm{~nm}$ in diameter. Nanoparticles synthesised at pH 5 included small spherical particles, similar to those dominating at $\mathrm{pH}$ 3. In addition a large number of bigger particles with well-defined shapes, including triangles, hexagons, spheres and rods also occurred at this $\mathrm{pH}$. The shapes of the particles formed at $\mathrm{pH} 7$ were similar to those formed at pH 9 and included small spherical particles as well as bigger particles with irregular, undefined shapes. These results are supported by previous studies suggesting that optimum gold accumulation by microbial cells normally occurs in the $\mathrm{pH}$ range of 2 to 6 (19) and test work performed with Lactobacillus showed that changes in the $\mathrm{pH}$ could have an effect on the size distribution of gold nanoparticles (28).

The variety in the shapes of particles formed at the different $\mathrm{pH}$ levels indicates that changes in this parameter would play an important role during optimisation of a process controlling particle morphology.

The behaviour of nanoparticle synthesis over a range of temperatures was determined by exposing $V$. luteoalbum and Isolate 6-3 biomass to $\mathrm{HAuCl}_{4}$ solutions at temperatures of 25,35 and $50^{\circ} \mathrm{C}$, respectively (Experiment 4). Samples for TEM analysis were collected after 1 and $24 \mathrm{~h}$ incubation and the trends in nanoparticle formation in $\mathrm{V}$. luteoalbum at 25 and $50^{\circ} \mathrm{C}$ are illustrated in Figure 5

The rate of formation of the nanoparticles was related to the incubation temperature and increased temperature levels allowed particle growth at a faster rate. At the lower temperatures, the majority of nanoparticles formed after $1 \mathrm{~h}$ exposure to the gold solution were spherical with an average diameter of less than $10 \mathrm{~nm}$. Further incubation for $24 \mathrm{~h}$ led to the number of smaller particles decreasing, whereas the number of larger particles, exhibiting well-defined shapes, increased. At $50^{\circ} \mathrm{C}$, no difference could be detected in the

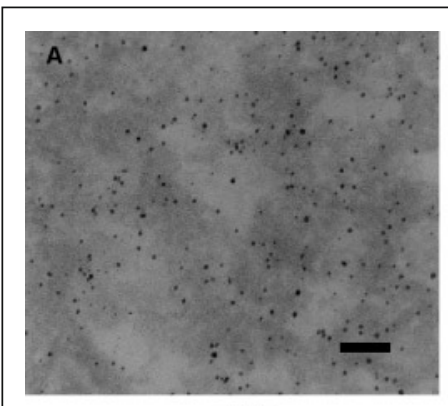

$\mathrm{pH} 3$

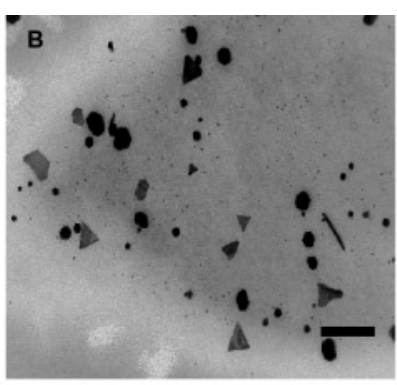

$\mathrm{pH} 5$

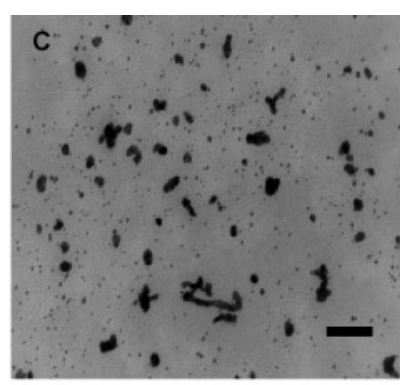

$\mathrm{pH} 7$

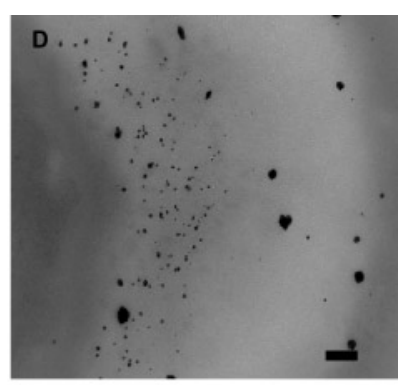

$\mathrm{pH} 9$

\section{Figure 4}

TEM images showing the effect of $\mathrm{pH}$ on nanoparticle formation in V. luteoalbum (Scale bar $=100 \mathrm{~nm})$ 


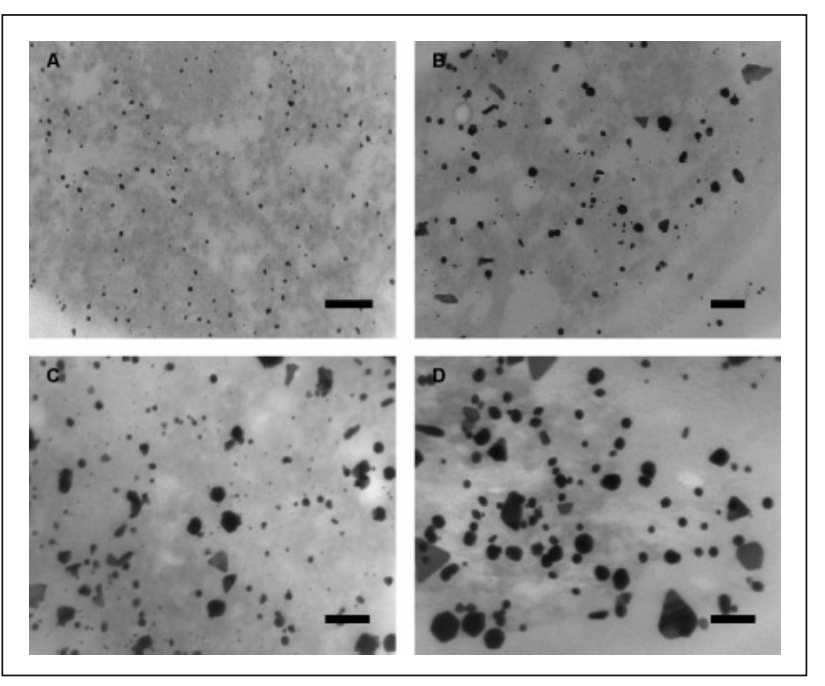

\section{Figure 5}

TEM images illustrating the effect of temperature on nanoparticle production in $\mathrm{V}$. luteoalbum cells. (A) $1 \mathrm{~h}$ exposure to $\mathrm{HAuCl}_{4}$ at $25^{\circ} \mathrm{C}$, (B) $24 \mathrm{~h}$ exposure to $\mathrm{HAuCl}_{4}$ at $25^{\circ} \mathrm{C}$, (C) $1 \mathrm{~h}$ exposure to $\mathrm{HAuCl}_{4}$ at $50^{\circ} \mathrm{C},(\mathrm{D}) 24 \mathrm{~h}$ exposure to $\mathrm{HAuCl}_{4}$ at $50^{\circ} \mathrm{C}$ (Scale bar $=100 \mathrm{~nm}$ )

size and morphology of particles produced after 1 and $24 \mathrm{~h}$ exposure to gold and very few small spherical particles were present. The effect of the rate of reduction on the shape of gold particles was previously described for the chemical synthesis of gold colloids in the presence of solvents (33). Formation of spherical particles was favoured at low reduction rates, whereas high reduction rates resulted in the formation of particles exhibiting nanorod and platelet-like morphologies.

The above results provide indications that the size of the nanoparticles can, to a large extent, be controlled by operating at low temperatures, which would allow particle formation at a slower rate.

\section{Production of gold nanoparticles using cell extracts}

The cultures used in this study produced gold nanoparticles intracellularly. From a process and applications point of view it would, however, be useful if the nanoparticles could form extracellularly, since it would eliminate the need to harvest the nanoparticles formed within the cells.

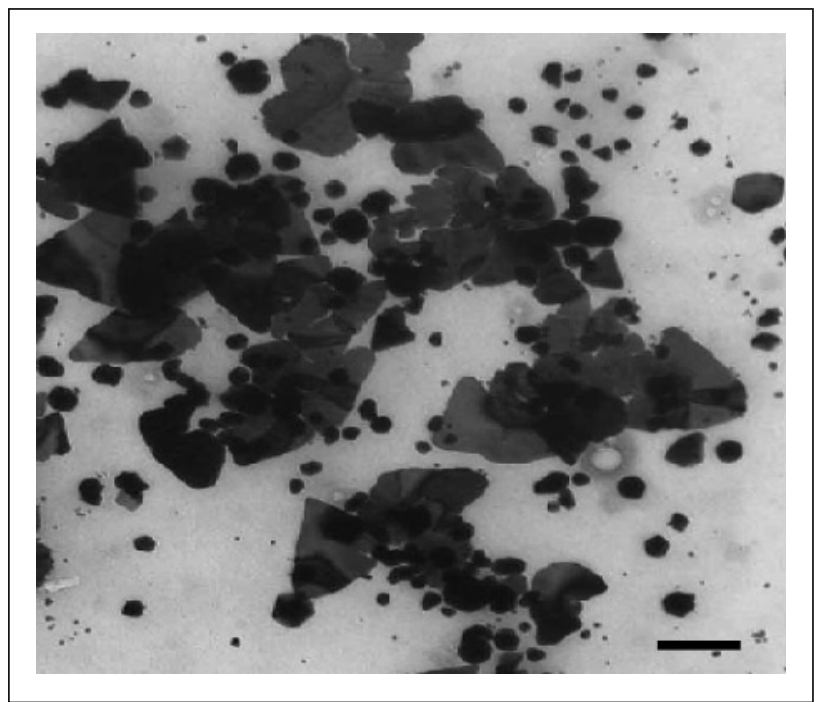

Figure 6

TEM image of gold particles formed after exposing cell-free extract from Verticillium to $\mathrm{HAuCl}_{4}$. (Scale bar $=200 \mathrm{~nm}$ )

It is speculated that gold ions are reduced by enzymes and proteins present in either the cell walls or cytoplasm of the organisms leading to the aggregation of the gold atoms and formation of nanoparticles (24). These assumptions are supported by research performed by Brown and colleagues (34) who used the crystallisation of gold as a model system to show that polypeptides could control the morphology of the resulting gold crystals. Identification of the active reducing proteins or enzymes involved in the process could potentially allow for a process in a cell-free environment, where the size and shape of the particles can be controlled.

A test, exposing cell-free extract to gold ions was performed to obtain an indication of whether reducing compounds are present in the cell extract and to assess if cell structures have a role to play in the formation of nanoparticles exhibiting specific sizes and shapes (Experiment 5).

Verticillium cells were broken using glass beads and the resultant extract exposed to gold ions. The morphologies of the particles were similar to those formed intracellularly (Figure 6), but included a large number of large thin plate-like structures, which were predominantly triangular or

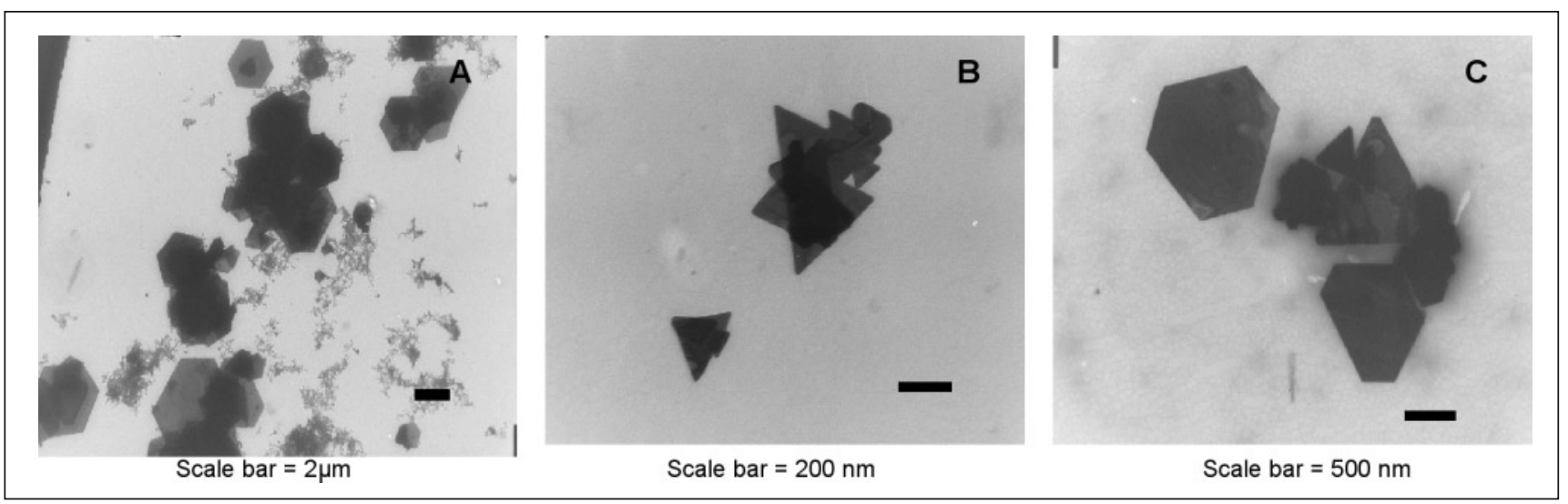

\section{Figure 7}

TEM images of a selection of gold nanoflakes synthesised in the presence of cell-free extract obtained from Verticillium 


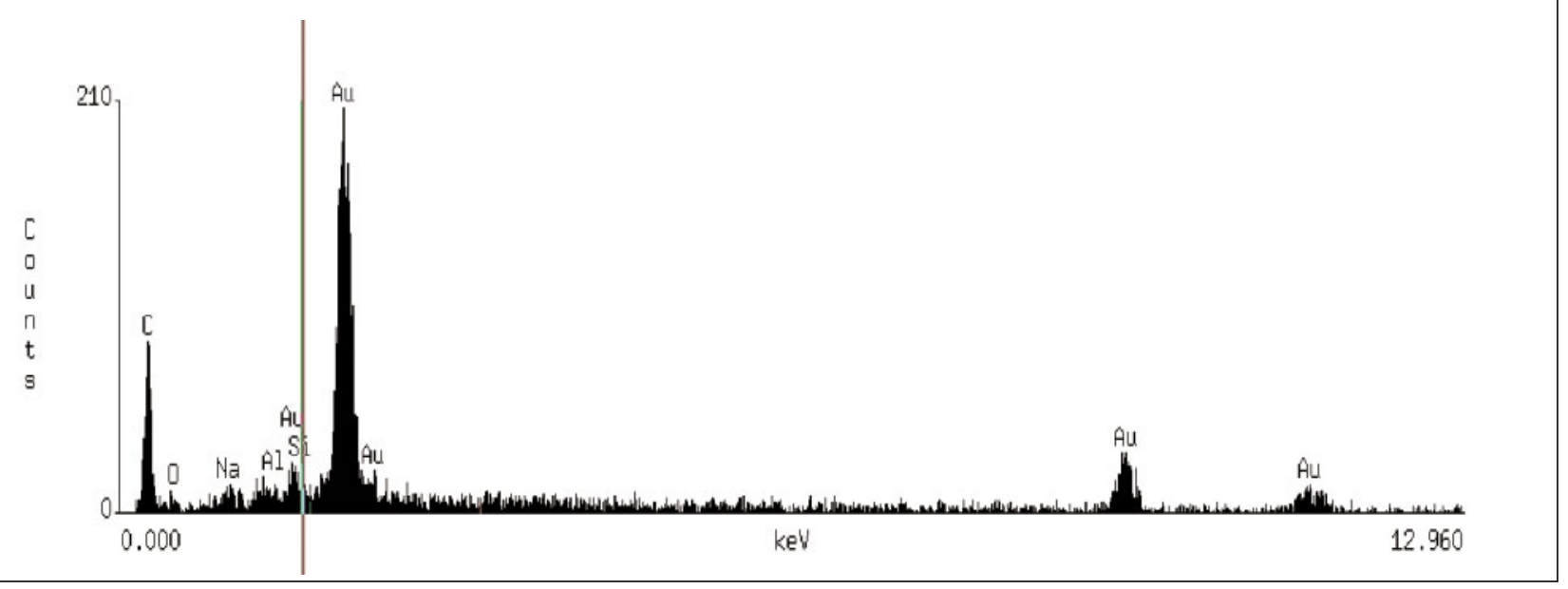

Figure 8

Spot-profile EDS spectrum for a gold nanoparticle formed after exposure to $\mathrm{HAuCl}_{4}$.

hexagonal in shape (Figure 7). Similar behaviour was observed during the synthesis of gold particles using broth prepared from Neem tree leaves (35). It is possible that without the constraints of a cell wall, bigger particles could form, but further test work is needed to confirm this. Since it is known that the size and shape of metal nanoparticles can change their optical and electronic properties (36), these gold plates can potentially be used in interesting applications in the areas of optics and sensor technology.

A spot profile EDS spectrum derived from one of the nanoparticles indicated that it was mainly composed of $\mathrm{Au}$ with trace amounts of $\mathrm{C}, \mathrm{O}, \mathrm{Na}, \mathrm{Si}$ and $\mathrm{Al}$ (Figure 8). It is not clear whether these trace elements were associated with the nanoparticles or if they were present in the vicinity of the particles.

The results imply that exposure of whole cells to the gold solution during nanoparticle formation is not necessary. Identification of the active reducing proteins or enzymes involved in the process could potentially allow for a process in a cell-free environment, where the size and shape of the particles can be precisely controlled.

\section{Conclusions}

The intracellular synthesis of gold nanoparticles of various morphologies and sizes in two fungal cultures, $V$. luteoalbum and Isolate 6-3, has been investigated. The rate of particle formation and therefore the size of the nanoparticles could, to an extent, be manipulated by controlling parameters such as the $\mathrm{pH}$ and temperature. The extracellular formation of gold nanoparticles after exposure of cell-free extract to gold ions was demonstrated. Extracellular formation of gold nanoparticles would be advantageous from a process point of view, since it would eliminate the need to recover the particles formed within the cells.

The development of chemical procedures to control the morphology of nanoparticles is an ongoing area of research.
A biological process with the ability to strictly control the shape of the particles produced would therefore be an exciting prospect. However, the cellular mechanism leading to the biosynthesis of gold nanoparticles is not yet fully understood. Further research will therefore focus on the development of a fundamental understanding of the process mechanism on a cellular and molecular level, including isolation and identification of the compounds responsible for the reduction of gold ions.

\section{Acknowledgements}

The authors would like to thank the sponsors of Project AuTEK and Mintek for financial support and permission to publish the results and Mr C van der Merwe at the Microscopy Unit, University of Pretoria, for his assistance.

\section{References}

1 T. Klaus-Joerger, R. Joerger, E. Olsson, and C-G. Granqvist, Trends Biotechnol., 2001, 19, 15

2 S. Mandal, S. Phadtare, and M. Sastry, Current Applied Physics, 2005, 5, 1218

3 C.W. Corti, and R.J. Holliday, Gold Bulletin, 2004, 37, 20

4 C.W. Corti, R.J. Holliday, and D.T. Thompson, Gold Bulletin, 2002, 35, 111

5 M.B. Cortie, Gold Bulletin, 2004, 37, 12

6 H. Huang, and X. Yang, Colloids and Surfaces A: Physicochem. Eng. Aspects, 2005, 255, 11

7 M-C. Daniel, and D. Astruc, Chem. Rev., 2004, 104, 293

8 M. Brust, and C.J. Kiely, Colloids and Surfaces A: Physicochem. Eng. Aspects, 2002, 202, 175

9 C. Burda, X. Chen, R. Narayanan, and M.A. El-Sayed, Chem. Rev., 2005, 105,1025

10 M. Kowshik, S. Ashtaputre, S. Kharrazi, W. Vogel, J. Urban, S.K. Kulkarni, and K.M. Paknikar, Nanotechnology, 2003, 14, 95 
11 R.M. Slawson, H. Lee, and J.T. Trevors, Biol. Metals, 1990, 3, 151

12 T.J. Beveridge, M.N. Hughes, H. Lee, K.T. Leung, R.K. Poole, I. Sawaidis, S. Silver, and J.T. Trevors, Advances in Microbial Physiology, 1997, 38, 177

13 I. Savvaidis, V.I. Karamushka, H. Lee, and J.T. Trevors, Biomaterials, 1998, 11, 69

14 A. Malik, Environment International, 2004, 30, 261

15 Y. Roh, R.J. Lauf, A.D. McMillan, C. Zhang, C.J. Rawn, J. Bai, and T.J. Phelps, Solid State Communications, 2001, 118, 529

16 T. Klaus, R. Joerger, E. Olsson, and C-G. Granqvist, PNAS, 1999, 96, 13611

17 M. Kowshik, N. Deshmukh, W. Vogel, J. Urban, S.K. Kulkarni, and K.M. Paknikar, Biotechnol. Bioeng., 2003, 78, 583

18 P. Yong, N.A. Rowsen, J.P.G. Farr, I.R. Harris, and L.E. Macaskie, Biotechnol. Bioeng., 2002, 80, 369

19 A. Nakajima, World J. Microbiol. Biotechnol., 2003, 19, 369

20 E.D. Korobushkina, V.I. Biryuzova, I.M. Korobushkin, and G.I. Karavaiko Gl, Dokl.Akad.Nauk SSSR, 1989, 304, 431

21 N. Kuyucak, and B. Volesky, Biorecovery, 1989, 1: 189

22 V. Armendariz, I. Herrera, J.R. Peralta-Videa, M. Jose-Yacaman, H. Troiani, P. Santiago, and J.L. Gardea-Torresdey, Journal of nanoparticle research, 2004, 6, 377

23 T.J. Beveridge, and R.G.E. Murray, J. Bacteriol., 1980, 141, 876

24 P. Mukherjee, A. Ahmad, D. Mandal, S. Senapati, S. Sainkar, M.I. Khan, R. Ramani, R. Parischa, P.V. Ajayakumar, M. Alam, M. Sastry, and R. Kumar, Angew. Chem., Int. Ed., 2001, 40, 3585
A. Ahmad, P. Mukherjee, S. Seapati, D. Mandal, M.I. Khan, R. Kumar, and M. Sastry, Colloids and Surfaces B: Biointerfaces, 2003, 28, 313

26 A. Ahmad, S. Senapati, M.I. Khan, R. Kumar, R. Ramani, V. Srinivas, and M. Sastry, Nanotechnology, 2003, 14, 824

27 A. Ahmad, S. Senapati, M.I. Khan, R. Kumar, and M. Sastry, Langmuir, 2003, 19, 3550

28 B. Nair, and T. Pradeep, Crystal Growth and Design, 2002, 2, 293

29 R. Wahl, M. Mertig, J. Raff, S. Selenska-Pobell, and W. Pompe, Advanced Materials, 2001, 13, 736

30 A.S. Blum, C.M. Soto, C.D. Wilson, J.D. Cole, M. Kim, B. Gnade, A. Chatterji, W.F. Ochoa, T. Lin, J.E. Johnson, and B.R. Ratna, Nanoletters, 2004, 4, 867

31 M. Gericke, and A. Pinches, Biological synthesis of metal nanoparticles, International Biohydrometallurgy Symposium, Cape Town, 25-29 September 2005

32 V.I. Biryuzova, E.D. Korobushkina, I.N. Pozmogova, and G.I. Karavaiko, Mikrobiologiya, 1987, 56, 209

33 C. Li, W. Cai, C. Kan, G. Fu, and L. Zhang, Materials Letters, 2004, 58, 196

34 S. Brown, M. Sarikaya, and E.J. Johnson, J. Mol. Biol., 2000, 299, 725

35 S.S. Shankar, A. Rai, A. Ahmad, and M. Sastry, Journal of Colloid and Interface Science, 2004, 275, 496

36 K.L. Kelly, E. Coronado, L.L. Zhao, and C.G. Schatz, J. Phys. Chem. B, 2003, 107, 668 